\title{
MicroRNA-302a/d inhibits the self-renewal capability and cell cycle entry of liver cancer stem cells by targeting the E2F7/AKT axis
}

Yu-Shui Ma ${ }^{1,2,3+}$, Zhong-Wei Lv ${ }^{2 \dagger}$, Fei Yu ${ }^{2 \dagger}$, Zheng-Yan Chang ${ }^{4 \dagger}$, Xian-Ling Cong ${ }^{5}$, Xiao-Ming Zhong ${ }^{6}$, Gai-Xia Lu' Jian Zhu ${ }^{7}$ and Da Fu ${ }^{1 *}$

\begin{abstract}
Background: There is increasing evidence that liver cancer stem cells (LCSCs) contribute to hepatocellular carcinoma (HCC) initiation and progression. MicroRNA (miRNA) plays a significant functional role by directly regulating respective targets in LCSCs-triggered HCC, however, little is known about the function of the miRNA-302 family in LCSCS.
\end{abstract}

Methods: MiRNAs microarray was used to detect the miRNAs involved in LCSCs maintenance and differentiation. Biological roles and the molecular mechanism of miRNA-302a/d and its target gene E2F7 were detected in HCC in vitro. The expression and correlation of miRNA-302a/d and E2F7 in HCC patients was evaluated by quantitative PCR and Kaplan-Meier survival analysis.

Results: We found that the miRNA-302 family was downregulated during the spheroid formation of HCC cells and patients with lower miRNA-302a/d expression had shorter overall survival (OS) and progression-free survival (PFS). Moreover, E2F7 was confirmed to be directly targeted and inhibited by miRNA-302a/d. Furthermore, concomitant low expression of miRNA-302a/d and high expression of E2F7 correlated with a shorter median OS and PFS in HCC patients. Cellular functional analysis demonstrated that miRNA-302a/d negatively regulates self-renewal capability and cell cycle entry of liver cancer stem cells via suppression of its target gene E2F7 and its downstream AKT/ $\beta$ catenin/CCND1 signaling pathway.

Conclusions: Our data provide the first evidence that E2F7 is a direct target of miRNA-302a/d and miRNA-302a/d inhibits the stemness of LCSCS and proliferation of HCC cells by targeting the E2F7/AKT/ $\beta$-catenin/CCND1 signaling pathway.

Keywords: HCC, LCSCs, miRNA-302a/d, E2F7, Prognosis

\section{Background}

Global morbidity of hepatobiliary malignancies, mainly hepatocellular carcinoma (HCC) and cholangiocarcinoma, has recently increased [1]. HCC has the third highest mortality rate out of all major malignant carcinomas worldwide [2]. Surgical resection, percutaneous ablation

\footnotetext{
* Correspondence: fu800da900@126.com

†Yu-Shui Ma, Zhong-Wei Lv, Fei Yu and Zheng-Yan Chang contributed equally to this work.

${ }^{1}$ Central Laboratory for Medical Research, Shanghai Tenth People's Hospital,

Tongji University School of Medicine, Shanghai 200072, China

Full list of author information is available at the end of the article
}

and liver transplantation are the standard treatments for HCC, however these are only applicable to a small proportion of patients with early disease [3]. Therefore, it is imperative to develop novel therapeutic strategies against HCC.

The high rate of recurrence and heterogeneity are the two major features of HCC [4]. Recent studies have suggested that liver cancer stem cells (LCSCs), which display the capacity for self renewal and differentiation, are located within the tumor bulk and are responsible for HCC initiation, progression, resistance to therapy

(c) The Author(s). 2018 Open Access This article is distributed under the terms of the Creative Commons Attribution 4.0 International License (http://creativecommons.org/licenses/by/4.0/), which permits unrestricted use, distribution, and 
and the hierarchical organization of tumor cells [5]. Moreover, based on the CSC theory, the presence of LCSCs may be of prognostic relevance in patients with $\mathrm{HCC}$ [6]. However, how LCSCs sustain their self-renewal remains largely unknown and the clinical significance of LCSCs is yet to be fully established.

MicroRNAs (miRNAs), a class of non-coding RNA molecules of 20-22 nucleotides, regulate the expression of target genes in a post-transcriptional manner. MiRNAs can effectively modulate various biological processes, including cell proliferation, migration, differentiation, and apoptosis [7-9]. Aberrant expression of miRNAs in a wide range of tumor types has been well established and known to functionally modulate various biological processes [10]. Accruing evidence has demonstrated that miRNAs play vital roles in regulating the self-renewal and tumorigenesis of CSCs in various types of cancer, including HCC [11-13]. Therefore, the dysregulation of specific miRNAs might serve as an effective biomarker for predicting prognosis in patients with cancer [14]. More importantly, previous studies have indicated that circulating miRNAs are stable enough to be detected in serum and plasma [15] and thus may be promising non-invasive biomarkers for the early detection and prognosis of cancers.

Because of the essential roles of LCSCs in initiation and recurrence, identification of key candidate miRNAs that regulate LCSCs and exploration of their therapeutic potential in HCC may be helpful for improving treatment [16]. To better identify the miRNAs involved in the LCSCs self-renewal and differentiation process, we analyzed the genome-wide transcriptional profiling with miRNA microarray in different stages of LCSC cells. We found that expression levels of several tumor-related miRNAs were altered during spheroid formation of HCC cell lines HepG2 and Huh7. Among these miRNAs, the miR-302 family was negatively correlated with stem cell phenotypes. We further demonstrated that miRNA-302a/d negatively regulated cell growth and spheroid formation, and promoted apoptosis of HCC cells via suppression of its target gene E2F7, which suggested that miRNA-302a/d and E2F7 might be potential tumor biomarkers for the diagnosis and treatment of HCC patients.

\section{Methods}

\section{Ethics statement}

The study was approved by the Ethics Committee of Shanghai Tenth People's Hospital, Tongji University School of Medicine (SHSY-IEC-P-15-19). Each participant provided a written informed consent before participating in this study. All specimens were handled and made anonymous according to ethical and legal standards.

\section{Acquisition of clinical specimens}

Fresh frozen tissue samples from HCC patients, who underwent surgical resection between 2008 and 2012, were obtained from the tissue bank of China-Japan Union Hospital and Shanghai Tenth People's Hospital. These samples included paired tumor and adjacent non-cancerous tissues $(n=34)$, as well as a large cohort of individual HCC biopsies $(n=119)$ (Additional file 1: Table S1). The histological typing of these tumors and staging were performed according to the Seventh Edition of the American Joint Commission on Cancer (AJCC) tumor-node-metastasis (TNM) staging system for HCC [17], and patient data was collected up to December 31, 2017. The clinical information recorded included the patient's characteristics (age and gender), tumor characteristics (tumor differentiation, diameter and number of foci), OS and DFS (Additional file 1: Table S1). The last follow-up was performed on May 30th 2018 by direct correspondence or phone interview. The occasion of mortality or tumor relapse was verified by patients or their relatives or from their medical records or the social security records. OS was analyzed for the months from the date of diagnosis to the time of mortality, regardless of the cause. DFS was defined as the period from the initial date of diagnosis to the time of tumor progression by computed tomography scan or to the time of mortality due to the disease.

\section{Cell lines}

Human liver cancer lines HepG2 and Huh7 were purchased from the Cell Bank of the Chinese Academy of Sciences (Shanghai, China) and cultured in DMEM media (Invitrogen, Carlsbad, USA) and supplemented with $10 \%(v / v)$ fetal bovine serum (FBS), $100 \mathrm{U} / \mathrm{ml}$ penicillin, and $100 \mathrm{mg} / \mathrm{ml}$ streptomycin. Cell lines were routinely tested for mycoplasma contamination, and have been authenticated with short-tandem repeat analysis. Cell culture was conducted at $37{ }^{\circ} \mathrm{C}$ in a humidified $5 \%$ $\mathrm{CO}_{2}$ incubator.

\section{Cell proliferation assays}

For the cell proliferation assays, 1,000 cells were seeded into 96-well plates to culture overnight. Next, CCK8 $(10 \mathrm{~L})$ reagent was then added to each well, the absorbance (A) was measured at $450 \mathrm{~nm}$ after $1 \mathrm{~h}$, and the relative cell viability rate was calculated. All experiments were performed in triplicate.

\section{Cell cycle synchronization}

For synchronization, cells were treated with $2 \mathrm{mM}$ thymidine for $18-24 \mathrm{~h}$, released for 8-10 h, then treated with thymidine for $16-18 \mathrm{~h}$. S phase (about $4 \mathrm{~h}$ post-release) and mitosis were monitored by Hoechst 33342 (Beyotime, Jiangsu, China) staining. G2 cells ( $8 \mathrm{~h}$ post-release) were 
not incorporating Hoechst 33342, and the DNA did not condense. Mitotic cells were collected by shake-off once the cells showed an increase in the mitotic index (about 8-13 $\mathrm{h}$ post-release). The adherent cells were washed with PBS and then lysed. This population is not mitotic and is predominantly in G0. Isolated cells were replanted in a complete medium and incubated $4 \mathrm{~h}$ before harvesting for G1 cells [18].

\section{Tumor sphere assays}

Cells were cultured as tumor spheres in DMEM containing $20 \mathrm{ng} / \mathrm{mL}$ hEGF (R\&D Systems, Minneapolis, MN), $10 \mathrm{ng} / \mathrm{mL}$ hbFGF (R\&D Systems), $4 \mathrm{mg} / \mathrm{mL}$ heparin sulfate (Sigma, St. Louis, MO), 0.15\% bovine serum albumin (BSA) (Sigma), and 1\% penicillin G-streptomycin [19]. Sphere forming capacity (SFC) was determined by the ability to form three-dimensional spheroids in culture over a period of three to seven days. For assessment of long term proliferation and fold expansion, spheres were disassociated and passaged every 7 days using 0.05\% trypsin-EDTA (Invitrogen). Sphere cultures were grown in low-adherent flasks (Nunc, Penfield, NY). Cells were counted using a CountessTM (Invitrogen) automated cell counter. To induce tumor stem cell differentiation, the cultured tumorspheres of HepG2 and Huh7 cells were in medium with $10 \%(\mathrm{v} / \mathrm{v}) \mathrm{FBS}$ for seven days at $37^{\circ} \mathrm{C}$ in a humidified chamber supplemented with $5 \% \mathrm{CO}_{2}$.

\section{Plasmid construction and transfection}

Overexpression of hsa-miR-302a/d and E2F7 was performed in the pMSCV retroviral plasmid. The miR-302a/d sponge plasmid was constructed by inserting eight tandemly arrayed miR-302a/d-binding sites into the 3'UTR of dsRed [20]. All constructs were confirmed by sequencing. The plasmids were transiently transfected to target cells with lipofectamin 2000 (Invitrogen, cat.11668). To generate stable lines of overexpression or sponge knockdown, the plasmids were packaged into retrovirus with the amphotropic Phoenix packaging cell line and infected into target cells, followed by puromycin/hygromycin selection of the infected cells.

\section{Luciferase reporter assays}

The human E2F7 3'-UTR oligonucleotides containing the wild-type (Wt) or mutant (Mut) miR-302a/d binding site were sub-cloned into the XhoI and NotI sites of the pGL3 luciferase reporter plasmid vector (Promega, Madison, WI). HeLa cells were seeded in 24-well plates and cultured for $24 \mathrm{~h}$, then, cells were co-transfected with either the Wt or Mut reporter plasmid. Forty-eight hours after transfection, luciferase assay was determined using the Dual-Luciferase kit (Promega, Madison, WI) [21].
RNA immunoprecipitation (RIP) assay

The EZ-Magna RIP Kit (Millipore, USA) was applied to conduct the RIP assay according to the product specification. Firstly, cells were collected and lysed in complete RIP lysis buffer. Then, the cell extract was incubated with RIP buffer containing magnetic beads conjugated to a human anti-Ago2 antibody (Millipore, USA). Samples were incubated with proteinase $\mathrm{K}$ with shaking to digest proteins and the immunoprecipitated RNA was isolated. Subsequently, the NanoDrop spectrophotometer was used to measure the concentration of RNA, and the purified RNA was subjected to real-time PCR analysis.

\section{RNA extraction and quantitative PCR (qPCR)}

Total RNA, including miRNAs from normal liver tissue, HCC samples and cell lines, was isolated with Trizol reagent (Life Technologies, Grand Island, NY, USA). RNA concentration and purity were measured with the Nanodrop 1000 spectrophotometer (Thermo Fisher Scientific, Waltham, MA, USA) and 1.5\% denaturing agarose gels, respectively. The cDNA was obtained from total RNA by reverse transcription, and the final RNA concentration used in the quantitative PCR reaction was $10 \mathrm{ng}$, qPCR was performed using the TaqMan universal PCR Kit (Life Technologies). The same amount of first-strand cDNA from each sample was used to detect the mRNA/miRNA expression levels using specific primers. Sequences of PCR primers are shown in the Additional file 1: Table S1. U6 and GAPDH were used as the endogenous controls, and the $2^{-\Delta \Delta C T}$ method was used to analyze expression levels [22].

\section{Western blotting}

Total protein from HepG2 and Huh7 cells was extracted using cell lysis buffer. Protein concentration was analyzed using standard procedures for Western blotting. After incubation with the appropriate horseradish peroxidase-conjugated secondary antibodies, the membranes were treated with an enhanced chemiluminescence reagent (Thermo Scientific, Dreieich, Germany), exposed to X-ray film (Kodak, Rochester, USA) and quantified by densitometry (Beckman, South Pasadena, Canada). The rabbit monoclonal antibody for CD133 (cat. ab216323), EpCAM (cat. ab32392), SOX2 (cat. ab92494), Nanog (cat. ab109250), AKT1 (cat. ab182729) and GAPDH antibody (cat. ab181602) were purchased from Abcam (Cambridge, UK) and used for western blot analyses. The rabbit polyclonal E2F7 antibody (Invitrogen, cat. PA5-68911) and goat anti-rabbit IgG (Merck) and goat anti-mouse IgG (Merck) antibodies were used for western blot analyses. Antibody dilutions were 1:1,000 for primary antibodies and 1:5,000 for secondary antibodies in western blotting. 


\section{Flow cytometry analysis}

Cell apoptosis was determined by flow cytometry analysis. Cells were collected, washed with cold PBS, fixed in cold $70 \%$ Ethanol, treated with DNase-free RNase (Sangon, RB473. $100 \mu \mathrm{g} / \mathrm{ml}$ ) and stained with $50 \mu \mathrm{g} / \mathrm{ml}$ Propidium iodide (Sangon, cat. P1112) and Annexin V-APC/7-AAD kit (KeyGEN, cat. KGA-1025). The cells were analysed using a Gallios flow cytometer (Beckman Coulter) to quantify the proportion of cells in apoptosis status. Cells were harvested by trypsinization and counted such that about $1 \times 10^{6}$ cells were used for the cell cycle analysis. The cells were washed in PBS, fixed in $70 \%$ ice-cold ethanol overnight at $4{ }^{\circ} \mathrm{C}$, and then washed in PBS and incubated in $1 \mathrm{~mL}$ staining solution $(20 \mathrm{mg} / \mathrm{mL}$ propidium iodide, $10 \mathrm{U} / \mathrm{mL}$ RNaseA) for $30 \mathrm{~min}$ at room temperature. The DNA content was measured by flow cytometry on a FACS Calibur system (Becton Dickinson), and the cell cycle distributions of the different populations were determined using "Flowjo" software (Verity Software House).

\section{Subcutaneous mouse xenografts}

A total of 80 male BALB/c nude mice (15-18 g), aged 4-5 weeks old, were purchased from Shanghai SLAC Laboratory Animal Co., Ltd., (Shanghai, China). Mice were equally divided into two groups $(n=6)$ and received a subcutaneous injection in their right flank of either $1 \times 10^{7}$ HepG2 and Huh7 cells stably expressing $\mathrm{miR}-302 \mathrm{a} / \mathrm{d}$ and/or E2F7. Mice were housed in an animal facility at a temperature of $25{ }^{\circ} \mathrm{C}$ and humidity of $60-70 \%$ and subjected to a $12 \mathrm{~h}$ light-dark cycle with ad libitum access to food and water. Tumor growth was monitored twice a week by size measurement. Both maximum (L) and minimum (W) diameters of the tumors were measured using a slide caliper, and the tumor volume was calculated as $\pi \mathrm{LW}^{2} / 6[23]$.

\section{Microarray analysis}

For microarray analysis of miRNA gene expression, Agilent Array platform was employed. The sample preparation and microarray hybridization were performed based on the manufacturer's standard protocols. Briefly, $1 \mu \mathrm{g}$ of total RNA from each sample was amplified and transcribed into fluorescent cDNA with using the manufacturer's Agilent's Quick Amp Labeling protocol (version 5.7, Agilent Technologies). Agilent Quick Amp Labeling Kit was used for sample labeling. Hybridization was performed in Agilent's SureHyb Hybridization Chambers. The labeled cRNAs were hybridized onto the Whole Human Genome Oligo Microarray $(4 \times 44 \mathrm{~K}$, Agilent Technologies). After having washed the slides, the arrays were scanned by the Agilent Scanner G2505B. Agilent Feature Extraction software (version 11.0.1.1) was used to analyze the acquired array images. Quantile normalization and subsequent data processing were performed using the GeneSpring GX v11.5.1 software package (Agilent Technologies).

\section{Bioinformatics analysis}

Hierarchical clustering was performed using the multiple experiment viewer $(\mathrm{MeV})$ 4.7.1 software programs: (http:// www.tm4.org $/ \mathrm{mev} /$ ). We used four online target-gene prediction software miRDB (http://mirdb.org/miRDB/), miRTarBase (http://mirtarbase.mbc.nctu.edu.tw/), miRanda (www.microrna.org) and RNA22 (http://cbcsrv.watson. ibm.com/rna22.html) to forecast several potential target genes of hsa-miR-302a/d. Subsequently, predicted target genes were subjected to KEGG pathway online analysis by DAVID (http://david.ncifcrf.gov).

\section{Statistical analysis}

Data is presented as mean \pm standard deviation. The $x^{2}$ was used to compare the differences of categorical variables and the Student's t-test was used for comparison of differences between two groups. Kaplan-Meier curves and the log-rank test were used to analyze the OS or DFS of HCC patients. All statistical analyses were performed using the SPSS 20.0 software program (SPSS Inc., Chicago, IL, USA). A $P$-value $<0.05$ was considered statistically significant.

\section{Results}

\section{In vitro formation and identification of tumor spheres} from HCC cell lines

HCC cell lines have distinct phenotypes and fall into well or poorly differentiated clusters [24, 25]. In this study, to obtain tumor spheres from HCC cell lines in vitro, two well-differentiated hepatocyte-derived carcinoma cell lines HepG2 and Huh7 cells were chosen and cultured as adherent monolayers. Both cell lines exhibited low expression of several CSC markers (Fig. 1a, b and Additional file 1: Figure S1A, B), thus likely to portray stem cell features. Cells were then transferred to stem cell medium containing EGF and bFGF. After 3 days in culture macroscopic and spherical or oval tumor spheres formed. Continuing proliferation led to a progressive 5- to 10-fold increase in the diameter of the tumor spheres over 7 days. The identification of CSC remains challenging and several CSC markers have been proposed. Among these marker, CD133 and EpCAM expression seems to better correlate the presence of LCSC and aggressiveness of liver tumors [26]. Our results showed that the cultured tumorigenic liver tumor spheres exhibited stem-like features with gradual and significantly increased expression of CD133 and EpCAM on the both mRNA (Fig. 1a) and protein (Fig. 1b) expression level.

Next, the expression level of stem cell markers connected to self-renewal and stemness capability was evaluated. To 


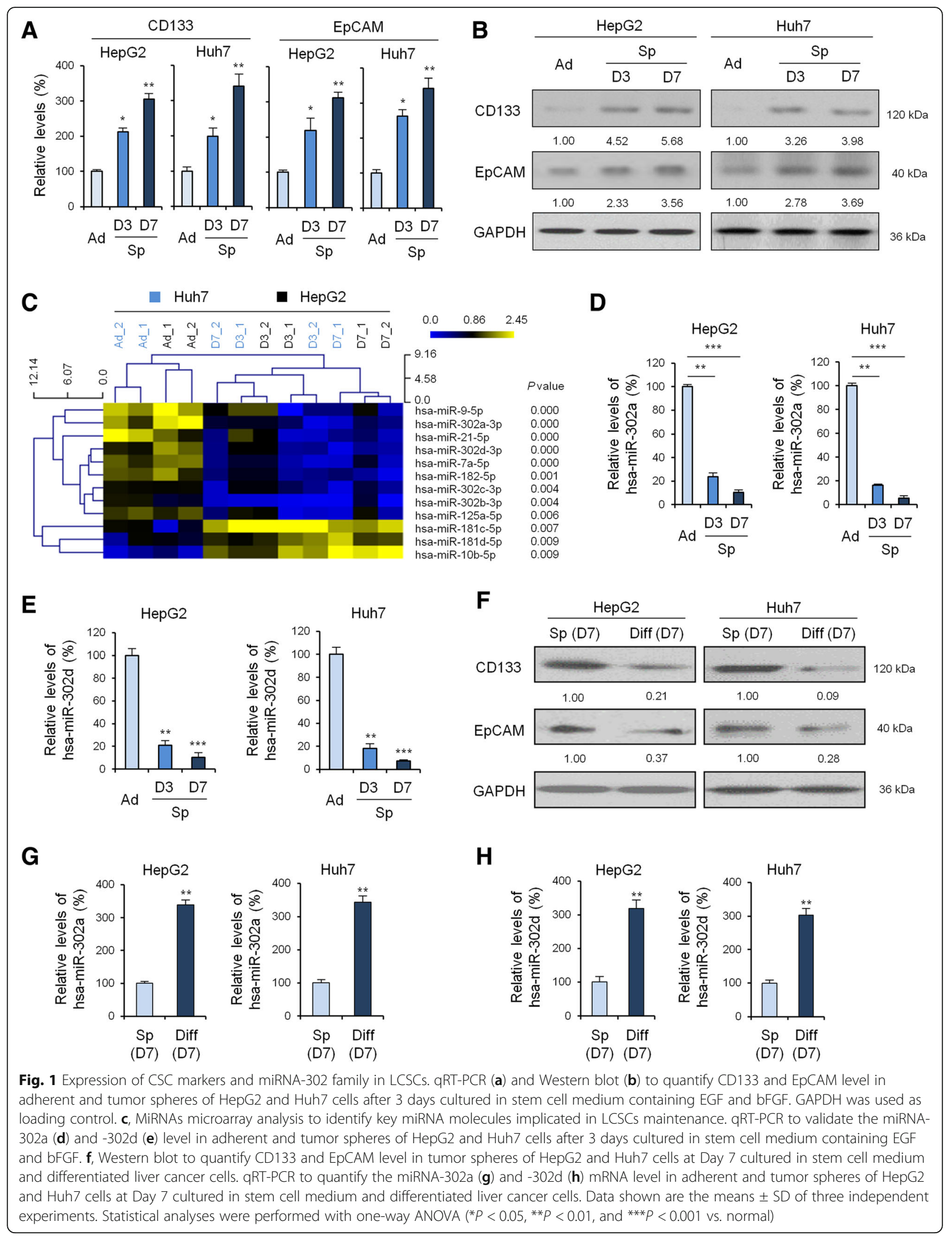


this end, we examined the gene expression of Sox 2 and Nanog transcripts in samples extracted from adherent vs. spheroids of HepG2 and Huh7 cells. As shown in Additional file 1: Figure S1A, the expression of Sox2 and Nanog were significantly increased in cell grown as spheres compared with those grown in adherence. The protein expression of Sox 2 and Nanog was also significantly increased in cells grown as spheres compared with those grown in adherence (Additional file 1: Figure S1B).

\section{MiRNA microarray analysis reveals that the miRNA-302 family is involved in LCSCs maintenance}

To identify key miRNA molecules and mechanisms implicated in LCSCs maintenance, we profiled the expression of miRNAs in these two HCC cell types. When compared with the expression levels of miRNAs from both sample groups, our results showed that the gene expression level of miRNA-302 family was gradually and significantly decreased during formation of tumor spheres from HepG2 and Huh7 cells (Fig. 1c).

To validate these differentially regulated miRNAs, we examined the expression of miRNA-302a, -302b, -302c, and $-302 \mathrm{~d}$ in RNA extracted from adherent vs. spheroids of HepG2 and Huh7 cells. As shown in Fig. 1d-e and Additional file 1: Figure S1C-D, the expression of the indicated transcripts, analyzed by real-time RT-PCR, were significantly decreased in cells grown as spheres compared with those grown in adherence. Among them, the expression levels of miRNA-302a and $-302 d$ in tumor spheres from HepG2 and Huh7 cells were significantly decreased when compared with the control group $(P<0.001)$ (Fig. $1 \mathrm{~d}, \mathrm{e})$.

\section{Differentiation and CSC markers expression of LCSCs}

Tumor spheres cultured in suspension may redifferentiate to adherent cells when cultured in routine medium containing serum. Therefore, we detected CSC marker expression in tumor spheres from HepG2 cells cultured in suspension with serum-free medium to maintain stemness or in monolayers with the addition of FBS to induce differentiation. Our data showed that the gene levels (Additional file 1: Figure S2A) and protein expression (Fig. 1f) of liver stem cell-associated genes (including CD133 and EpCAM) in re- differentiated cells were significantly reduced following FBS treatment. Moreover, the gene levels (Additional file 1: Figure SB) and protein expression (Additional file 1: Figure S2C) of stem cell-associated genes (including Sox2 and Nanog) in re-differentiated cells were also significantly reduced following FBS treatment. Conversely, the expression of miRNA-302 family was significantly increased in adherent HepG2 and Huh7 cells when compared with tumor spheres cultured in suspension (Fig. 1g-h and Additional file 1: Figure S2D-E).
To exclude the possible effects of serum, expression levels of miRNA-302a and -302d mRNA in HepG2 and Huh7 cells were investigated after culture in DMEM supplemented with either 5, 10 or $15 \%$ FBS. The qPCR analyses revealed that changes in serum concentration had no effect on the expression levels of miRNA-302a (Additional file 1: Figure S2F) and -302d (Additional file 1: Figure S2G), indicating that the observed changes in miRNA-302a and -302d expressions were associated with stemness and not serum concentration. Moreover, to exclude the possible effects of additional growth factors, expression levels of miRNA-302a and -302d mRNA in HepG2 and Huh7 cells were investigated after culture in DMEM supplemented with or without additional growth factors. The qPCR analyses revealed that additional growth factors had no effect on the expression levels of miRNA-302a and -302d (Additional file 1: Figure $\mathrm{S} 2 \mathrm{H}$ ), indicating that the observed changes in miRNA-302a and $-302 d$ expressions were associated with stemness and not additional growth factors.

\section{MiRNA-302a/d inhibits proliferation and spheroid formation and promotes cellular apoptosis in HCC cells} To investigate the biological role of miRNA-302a/d in HCC cells, we performed loss- and gain-of-function studies using sponge (Fig. 2a) and overexpressed plasmid (Fig. 2b) in HepG2 and Huh7 cells. As shown in Fig. 2c and $d$, suppression of miRNA-302a/d significantly enhanced the spheroid formation and growth rate of HepG2 and Huh7 cells transfected with the miRNA-302a/d sponge plasmid compared with the negative control-transfected cells. Moreover, suppression of miRNA-302a/d significantly decreased the cellular apoptosis of HepG2 and Huh7 cells transfected with the miRNA-302a/d sponge plasmid compared with the negative control- transfected cells (Fig. 2e). However, spheroid formation and cellular growth assay revealed that following miRNA-302a/d overexpression, the spheroid formation (Fig. 2f) and growth rate (Fig. 2g) of HepG2 and Huh7 cells were significantly inhibited when compared to the control group. Cellular apoptosis assay revealed that following miRNA-302a/d overexpression, the cellular apoptosis of HepG2 and Huh7 cells were significantly increased when compared to the control group (Fig. 2h).

\section{MiR-302a/d directly targets E2F7 in human HCC cells}

Although the large majority of miRNA targets remain unknown, there is evidence for redundant target specificity of unrelated miRNAs, or miRNAs from the same family [27]. Next, we searched for potential target genes of miR-302a/d using four publicly available databases including miRanda, RNA22, miRDB and miRTarBase to predict the potential target genes of miRNA-302 family. 


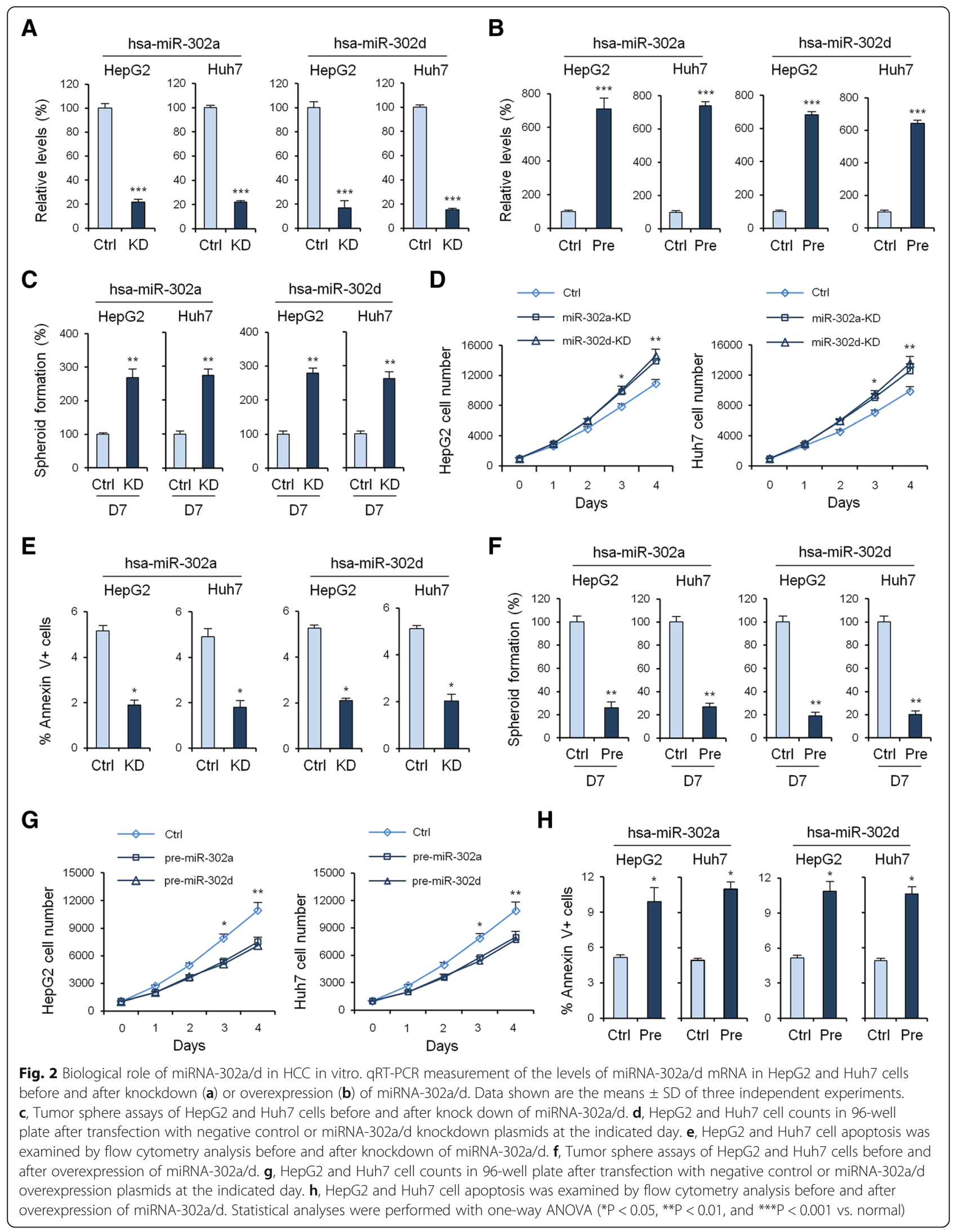


The result showed that there were 125 and 83 common predicted target genes for miR-302a and $-302 \mathrm{~d}$ (Fig. 3a), respectively. Of these, 4 common genes were predicted as the targets for miR-302a and $-302 \mathrm{~d}$, including 2 reported genes (AKT1 [28] and cyclin D1 [29]) and 2 previously unreported potential target genes (E2F7 and KPNA2) (Fig. 3b). Subsequently, predicted target genes were subjected to KEGG pathway analysis and the results revealed some important cancer and stem-related pathways including metabolic pathways, apoptosis, pathways in cancer, focal adhesion, Notch and PI3K-Akt signaling pathway (Fig. 3c), in which the transcription factor E2F7 was a candidate involved in tumorigenesis and cancer stemness in HCC. Moreover, the mRNA level of KPNA2 was undifferentiated in cells grown as spheres compared with those grown in adherence (Fig. 3c). Thus, in our current study, we were particularly interested in E2F7 expression and its correlation with miR-302a and -302d.

The expression of E2F7 is associated with cell cycle and E2F7 RNA and protein levels oscillate through the cell cycle with the highest expression levels during S-phase [30]. Therefore, we detected E2F7 mRNA level after treatment of miR-302a/d knockdown or overexpression in synchronized HepG2 and Huh7 cells to determine whether $\mathrm{miR}-302 \mathrm{a} / \mathrm{d}$ really altered the expression levels of E2F7 independent of its effects on cellular proliferation. When compared to the control group, the gene expression of E2F7 was significantly higher in miRNA-302a/d knockdown group $(P<0.01)$ (Fig. 3d, Additional file 1: Figure S3A-B) and was significantly lower in the miRNA-302a/d overexpression group $(P<0.01)$ (Fig. 3e), which suggested that E2F7 was regulated by miRNA-302a/d and was negatively correlated with miRNA-302a/d.

Next, to further test the regulation role of miRNA-302a/ d on E2F7 at the protein level, we used Western blot analysis to measure the protein levels of E2Fs family members (E2F1, E2F7, and E2F8) and AKT1, a reported downstream protein after miRNA-302a/d overexpression or knockdown. The results suggested that the increase in miRNA-302a/d levels significantly decreased E2F7 protein expression and had the same tendency in AKT1 and vice versa (Fig. 3f). However, there was no obvious change of the protein levels of E2F8, another atypical E2F family member, and E2F1, which participates in the self-renewal and differentiation of stem cells, after miRNA-302a/d overexpression or knockdown (Fig. 3f).

Next, by using bioinformatics analysis, we found that miRNA-302 family contained specific binding sequence of the 3'-UTR region of E2F7 gene. The 3'-UTR binding site and mutation site of miRNA-302a/d of E2F7 gene are shown in Fig. 3g. We performed a luciferase reporter assay to further verify whether miRNA-302a/d directly targeted E2F7. As shown in Fig. 3h and i, ectopic expression of miRNA-302a/d decreased the luciferase activity of the 3'-UTRs of E2F7. However, miRNA-302a/d mutant containing three altered nucleotides in the seed sequence did not have an inhibitory effect on luciferase activity.

To further confirm that hsa-miR-302a/d directly interacts with E2F7 mRNA, we tested hsa-miR-302a/d-mediated binding of RISC to E2F7 mRNA using the Ago2-based ribonucleoprotein-IP assay (RIP-IP). One irrelevant/binding miRNA was used as a negative control. As shown in (Fig. 3j), the Ago 2 co-IP fraction from cells treated with the hsa-miR-302a/d mimic was significantly enriched for E2F7 mRNA compared to cells treated with control miRNA mimics.

\section{Expression of E2F7 in formation and differentiation of LCSCs}

Next, we analyzed the gene expression of E2F7 in formation and differentiation of LCSCs to explore the association between liver cancer stemness and E2F7 level. The results showed that the gene expression (Fig. 4a) and protein level (Fig. 4b) of E2F7 was gradually and significantly increased during formation of tumor spheres in HepG2 and Huh7 cells. Moreover, when analyzing the correlation of miRNA-302a/d and E2F7 gene in adherent vs. spheroids of HepG2 and Huh7 cells, we found that the relative expression level between miRNA-302a/d and E2F7 presented an inverse correlation (Additional file 1: Figure S3C, D).

Instead, the gene levels (Fig. 4c) and protein expression (Fig. 4d) of E2F7 in re-differentiated cells were significantly reduced following FBS treatment and the gene level of E2F7 was negatively correlated with miRNA-302a or miRNA-302d in adherent HepG2 and Huh7 cells when compared with tumor spheres cultured in suspension (Additional file 1: Figure S3E, F).

\section{Biological role of E2F7 in $\mathrm{HCC}$ in vitro}

To investigate the biological role of E2F7 in HCC, we performed gain-of-function studies using E2F7 overexpression on HepG2 and Huh7 cells (Additional file 1: Figure S4A, B). As shown in Fig. 4e and f, overexpression of E2F7 significantly enhanced the spheroid formation and growth rate of HepG2 and Huh7 cells transfected with the E2F7 overexpression plasmid compared with the negative control-transfected cells. Moreover, overexpression of E2F7 significantly decreased the cellular apoptosis of HepG2 and Huh7 cells transfected with the E2F7 overexpression plasmid compared with the negative control-transfected cells (Fig. 4g). These results indicated that E2F7 may be involved in stemness and proliferation in $\mathrm{HCC}$ in vitro. 


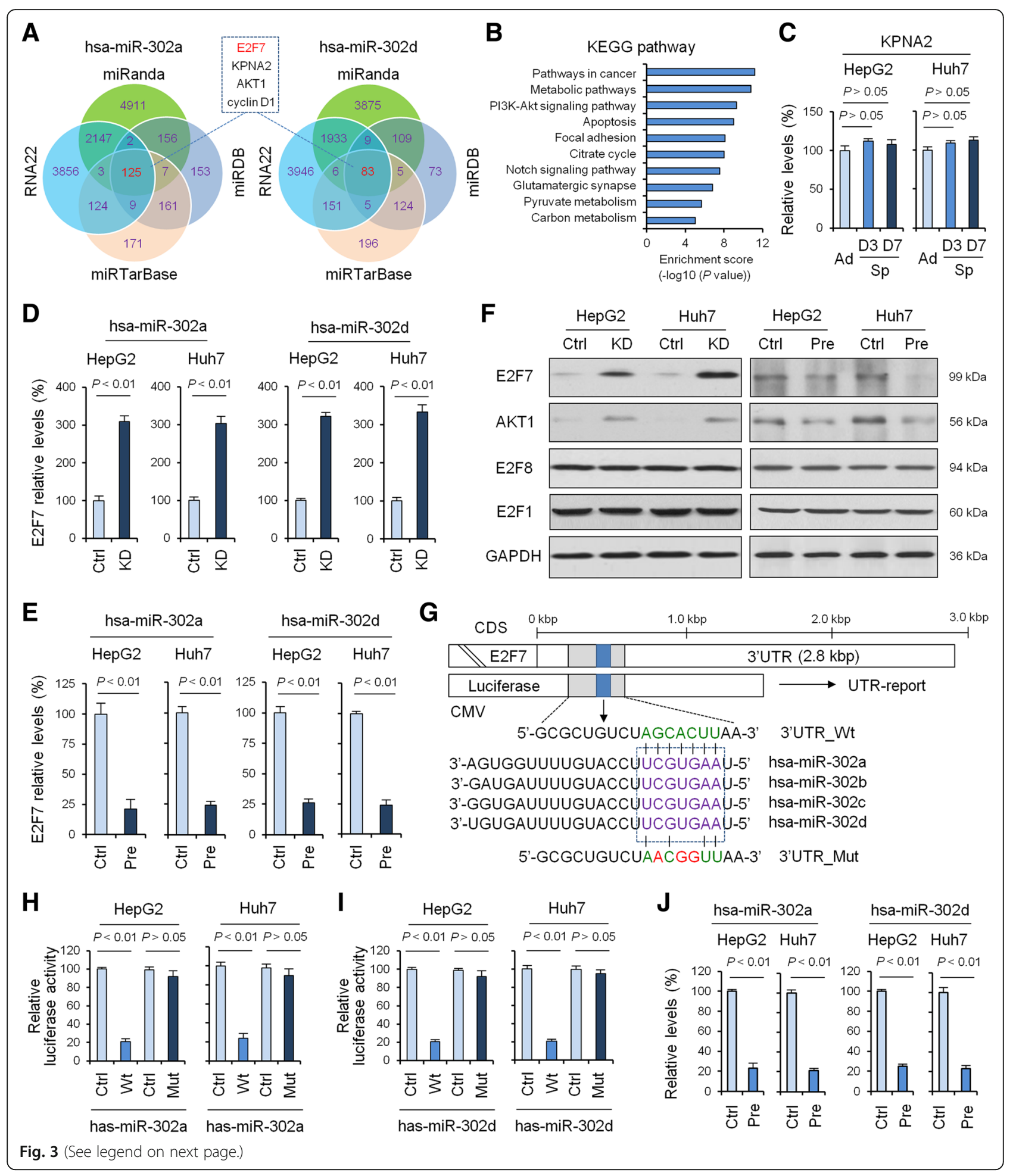




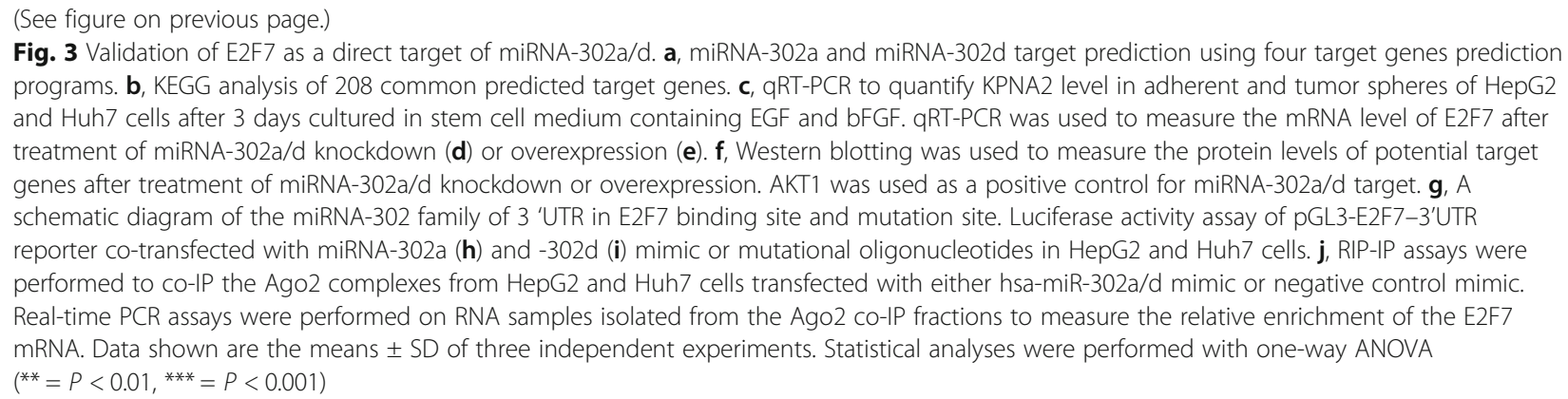

Next, we stably overexpressed both miRNA-302a/d and E2F7 in HepG2 and Huh7 cells (Additional file 1: Figure S4C-F). As expected, E2F7 overexpression abolished the effects of miRNA-302a/d in liver cancer cell spheroid formation (Fig. 4h). Similarly, with forced expression of E2F7, miRNA-302a/d was incapable of suppressing the cancer cell growth (Additional file 1: Figure S4G, H). Furthermore, cellular apoptosis was reduced in HepG2 and Huh7 cells when miRNA-302a/d and E2F7 were both overexpressed (Fig. 4i). Importantly, upon evaluating the effect of overexpression of both miRNA-302a/d and E2F7 on the model of HepG2 and Huh7 tumor cells subcutaneously implanted in nude mice, our results showed that overexpression of E2F7 abolished the effects of miRNA-302a (Fig. 4j) and miRNA-302d (Fig. 4k). Hence, our results showed that in the presence of E2F7 overexpression, miRNA-302a/d failed to inhibit proliferation of liver cancer cells in vitro and in vivo, which suggested that miRNA-302a/d inhibits cancer cell stemness and proliferation and promotes liver cancer cell apoptosis through suppressing E2F7.

\section{MiRNA-302a/d inhibits the spheroid formation of LCSCs through restrained cell cycle entry}

Knockdown of miR-302a/d led to significant G1 arrest or delayed the entry of $S$ phase in HepG2 and Huh7 cells as compared with control (Fig. 5a), suggesting that $\mathrm{miR}-302 \mathrm{a} / \mathrm{d}$ inhibits cell proliferation and cell cycle entry through the AKT1-p27 $7^{\mathrm{Kip} 1} / \mathrm{p} 21^{\mathrm{Cip} 1}$ pathway.

To further understand how miRNA-302a and -302d inhibits the spheroid formation of LCSCs, the levels of cell cycle regulatory pathway protein AKT1 and its downstream effectors were analyzed by Western blotting. Levels of both total AKT1 and phosphorylated AKT (p-AKT) were enhanced in miR-302a/d-knock down HepG2 and Huh7 cells compared to the corresponding control cells (Fig. 5b). Expression of AKT's downstream effector, cyclin D1, was also elevated. However, expression of total GSK3 $\beta$ and phosphorylated GSK3 3 , cyclin-dependent kinase (CDK) inhibitors $\mathrm{p} 27^{\mathrm{Kip} 1}$ and $\mathrm{p} 21^{\mathrm{Cip} 1}$, was down-regulated (Fig. 5b). On the contrary, overexpression of miR-302a/d led to significant G1 entry in HepG2 and Huh7 cells as compared with control (Fig. 5c). Moreover, with miR-302a/d overexpression, levels of total AKT1 and p-AKT were notably reduced as expected, as well as cyclin D1 (Fig. 5d). Inversely, total GSK3 $\beta$ and phosphorylated GSK3 $\beta$, and cell cycle inhibitors $\mathrm{p} 27^{\text {Kip1 }}$ and $\mathrm{p} 21^{\text {Cip1 }}$ expression were elevated accordingly after HepG2 and Huh7 cells were transfected with $\mathrm{miR}-302 \mathrm{a} / \mathrm{d}$ precursors or control.

\section{E2F7 activates AKT1-cyclin D1 signaling and the downstream cell cycle}

In order to illustrate whether the observed downregulation of E2F7 during overexpression of miR-302a/d was related to the reduced proliferation rate, we overexpressed the E2F7 lacking the 3'-UTR region (E2F7 CDS) into miR-302a/d-transfected HepG2 cells to determine the role of E2F7 on AKT1 signaling and downstream cell cycle. Interestingly, we found that E2F7 not only enhanced levels of phospho-Akt, but also significantly increased the expression of cell cycle related gene cyclin D1. In addition, total GSK3 $\beta$ and phosphorylated GSK3 $\beta$, p21, and p27 were downregulated after E2F7 overexpression (Fig. 5e). Overexpression of E2F7 led to significant G1 entry or promoted the entry of S phase in HepG2 and Huh7 cells as compared with control (Fig. 5f). Moreover, overexpression of E2F7 in miR-302a/d-transfected HepG2 cells led to significant G1 entry or promoted the entry of $S$ phase in $\mathrm{CD}_{133}{ }^{+} / \mathrm{EpCAM}^{+}$hepatoma cells as compared with control (Fig. 5f), suggesting that E2F7 promotes cell cycle

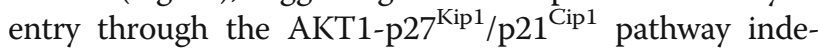
pendent of miR-302a/d.

\section{MiR-302a/d collaborates with E2F7 to regulate $\beta$-catenin/ CCND1 signaling}

Cyclin D1, a major downstream target gene of Wnt signaling, was remarkably decreased in miR-302a/d overexpression cells (Fig.5c), indicating that the Wnt pathway may be involved in miR-302a/d and E2F7 functions during spheroid formation and cell cycle entry of LCSCs. We further examined the protein level of the key upstream regulator, $\beta$-catenin, in HCC cells with miR-302a/d knockdown and/or E2F7 overexpression by Western blot analysis, which showed that the levels of intranuclear 


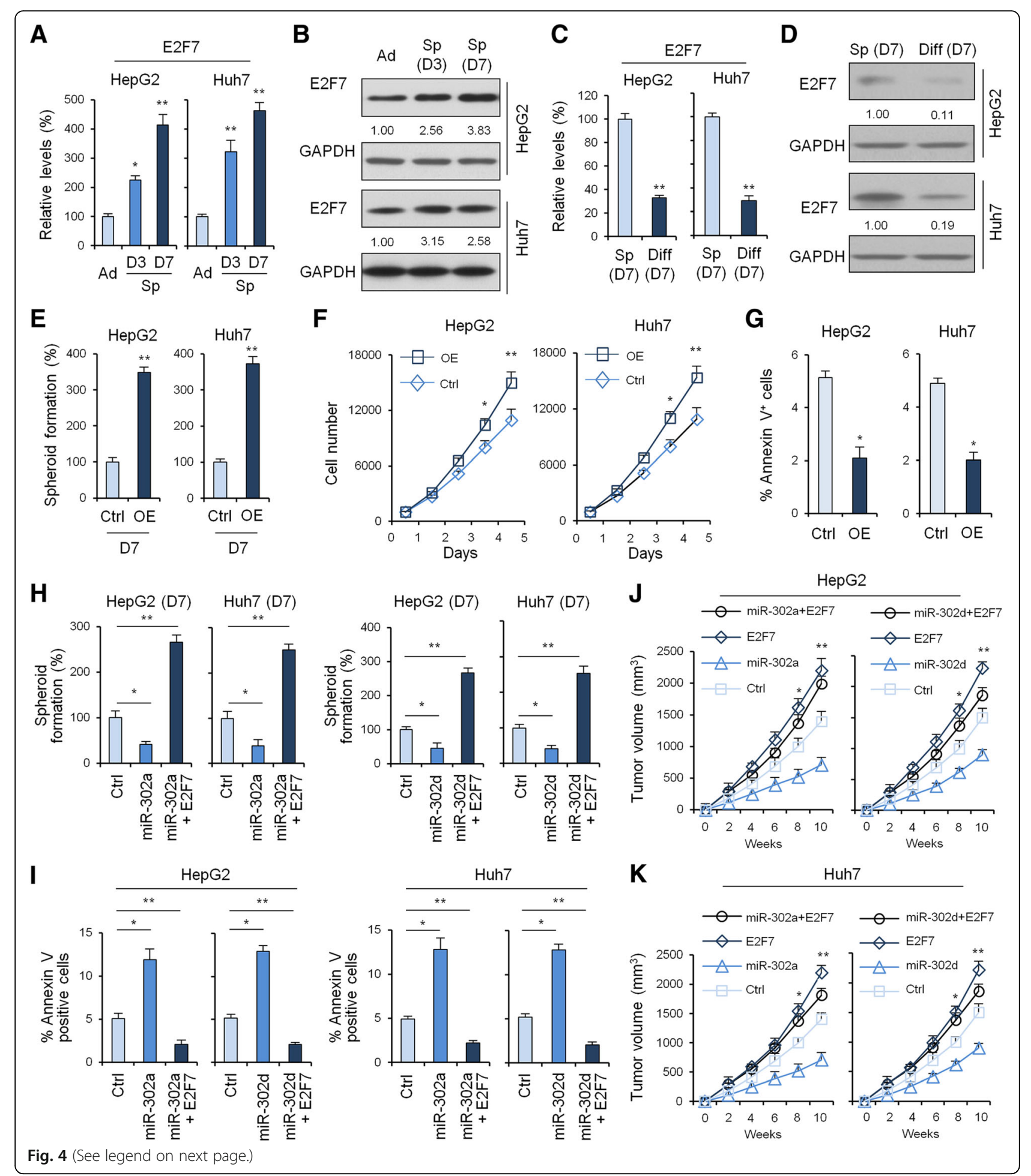


(See figure on previous page.)

Fig. 4 Biological role of miRNA-302a/d and E2F7 in HCC in vitro and in vivo. qRT-PCR (a) and Western blot (b) to quantify E2F7 levels in adherent and tumor spheres of HepG2 and Huh7 cells after 3 and 7 days cultured in stem cell medium containing EGF and bFGF. GAPDH was used as loading control. QRT-PCR (c) and Western blot (d) to quantify E2F7 levels in tumor spheres of HepG2 and Huh7 cells at Day 7 cultured in stem cell medium and differentiated liver cancer cells. e, Tumor sphere Assays of HepG2 and Huh7 cells before and after overexpression of E2F7. f. HepG2 and Huh7 cell counts in 96-well plate after transfection with negative control and E2F7 overexpression plasmids at the indicated day. g. HepG2 and Huh7 cell apoptosis was examined by flow cytometry analysis before and after overexpression of E2F7. Statistical analyses were performed with one-way ANOVA ( ${ }^{*} \mathrm{P}<0.05$, ${ }^{*} \mathrm{P}<0.01$, and ${ }^{* *} \mathrm{P}<0.001$ vs. normal). $\mathbf{h}$, Tumor sphere assays of HepG 2 and Huh7 cells before and after overexpression of miRNA-302a/d and/or E2F7. i, HepG2 and Huh7 cell apoptosis was examined by flow cytometry analysis before and after overexpression of miRNA-302a/d and/or E2F7. The subcutaneous tumor capacity of HepG2 and Huh7 cells before and after overexpression of miRNA-302a (j) and miRNA-302d (k) and/or E2F7 was detected. Statistical analyses were performed with one-way ANOVA $\left({ }^{*} \mathrm{P}<0.05,{ }^{* *} \mathrm{P}<0.01\right.$, and ${ }^{* *} P<0.001$ vs. normal)

$\beta$-catenin were strikingly enhanced (Fig. 5h). On the contrary, levels of intranuclear $\beta$-catenin were reduced in pre-miR-302a/d-transfected HepG2 cells compared to the corresponding control cells (Fig. 5h).

\section{Feedforward regulatory E2F7 signaling by AKT/CCND1 axis}

Since E2F7 is known to be highly expressed in proliferating cells and its RNA and protein levels oscillate through the cell cycle with the highest expression levels during S-phase [31], we next determined whether AKT/CCND1 axis altered the expression levels of E2F7 dependent of its effects on cellular proliferation and cell cycle. Our results showed that overexpression of AKT or CCND1 significantly enhanced the protein levels of E2F7 in HepG2 and Huh-7 cells transfected with AKT (Fig. 5i) or CCND1 (Fig. 5j) when compared to the corresponding control cells. Moreover, levels of intranuclear $\beta$-catenin were also enhanced in HepG2 and Huh-7 cells transfected with AKT (Fig. 5k) or CCND1 (Fig. 5l) when compared to the corresponding control cells.

\section{Expression and correlation of miRNA-302a/d and E2F7 in HCC}

Next, we validated the expression levels of miRNA-302a/d and E2F7 in HCC tissue samples using qRT-PCR in 154 HCC biopsies, 34 of which were pairs of tissue from para-carcinoma tissues. MiRNA-302a level was downregulated in HCC tissues ( $\mathrm{FC}=0.42, P=0.021$ ) (Fig. 6a). When compared with normal liver tissues, the levels of miRNA-302d displayed a 0.37 -fold decrease $(P=0.016)$ in 154 HCC biopsies (Fig. 6a). However, E2F7 expression analysis by qRT-PCR demonstrated that its expression levels were significantly higher in 154 HCC tumor biopsies relative to adjacent non-neoplastic tissues. This difference was statistically significant ( $\mathrm{FC}=4.86, P=0.005$, Fig. 6a).

Moreover, our results showed that E2F7 expression was negatively correlated with miRNA-302a/d expression in both normal liver tissues $\left(n=34, \mathrm{R}^{2}=0.48\right.$ and 0.52 , respectively, Fig. $6 \mathrm{~b}$ ) and HCC tumor biopsies $\left(n=154, \mathrm{R}^{2}=0.63\right.$ and 0.66 , respectively, Fig. $6 \mathrm{c}$ ). The expression level of E2F7 was downregulated in the
miRNA-302a/d-high expression samples, and upregulated in the miRNA-302a/d-low expression samples (Fig. 6b, c).

\section{Expression and correlation of miRNA-302a/d and E2F7 in LCSCs}

Considering the close association of miRNA-302a/d with E2F7 in HCC cell lines and tissues, we next investigated the expression and correlation of miRNA-302a/d and E2F7 in LCSCs extracted from the human tissue specimen. Our results showed that miRNA-302a/d expression was significantly lower in CSC-enriched LCSCs compared with FACS-sorted CD133- ${ }^{-}$pCAM $^{-}$HCC cells (Fig. 6d). Moreover, a cluster of $\mathrm{CD} 133^{+} / \mathrm{EpCAM}^{+}$hepatoma cells, which have been considered liver CSCs, exhibited enhanced E2F7 expression compared with the CD133-Ep$\mathrm{CAM}^{-}$cells (Fig. 6d). As expected, a negative correlation between miRNA-302a/d expression and the levels of E2F7 was observed in $\mathrm{CD} 133^{+} / \mathrm{EpCAM}^{+}$hepatoma cells (Fig. 6e).

\section{Clinical significance of miRNA-302a/d and E2F7 in HCC}

We then evaluated the prognostic value of miRNA302a/d and E2F7 expression for patients with HCC. The overall survival (OS) and progression-free survival (PFS) in patients with a high expression of miRNA-302a or miRNA-302d was prolonged relative to patients with low expression of miRNA-302a or miRNA-302d (Fig. 6f). Next, we further explored the clinical significance of E2F7 in HCC patients. Our results indicated that E2F7 expression was positively correlated with lower OS $(P=$ $0.002)$ and PFS $(P=0.009)$ (Fig. 6f) in HCC patients.

Since the data had suggested that E2F7 expression level was negatively correlated with miRNA-302a/d expression, and E2F7 was a direct target of miRNA-302a/ $\mathrm{d}$, we further examined the prognostic value of E2F7 expression together with miRNA-302a/d levels using multivariate analysis of OS and PFS. The results showed that HCC patients with high E2F7 expression and low miRNA-302a levels had significantly decreased OS $(P=$ $0.001)$ and PFS $(P=0.002)$ (Fig. 6g). Similarly, HCC patients with high E2F7 expression and low miRNA-302d 


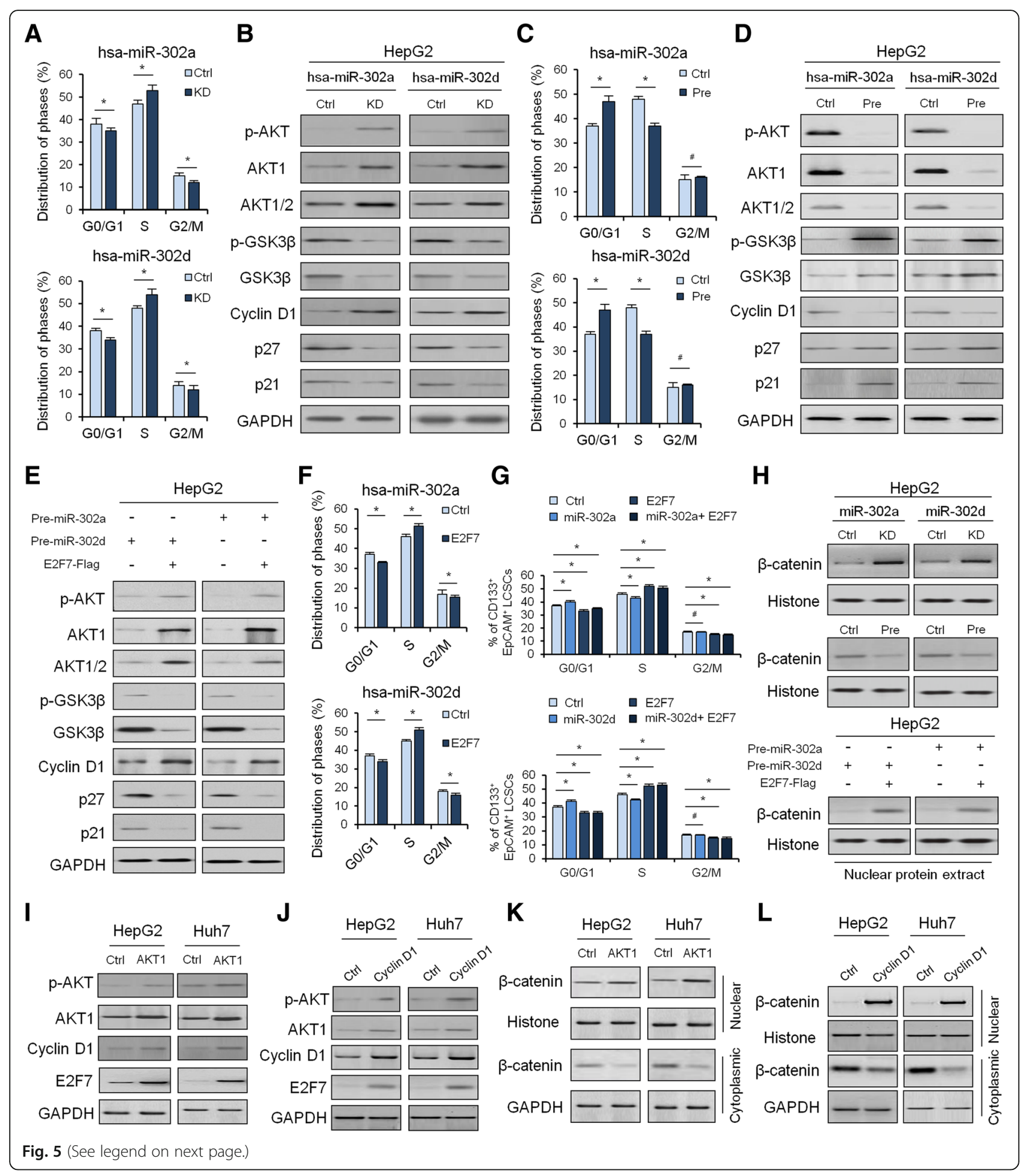




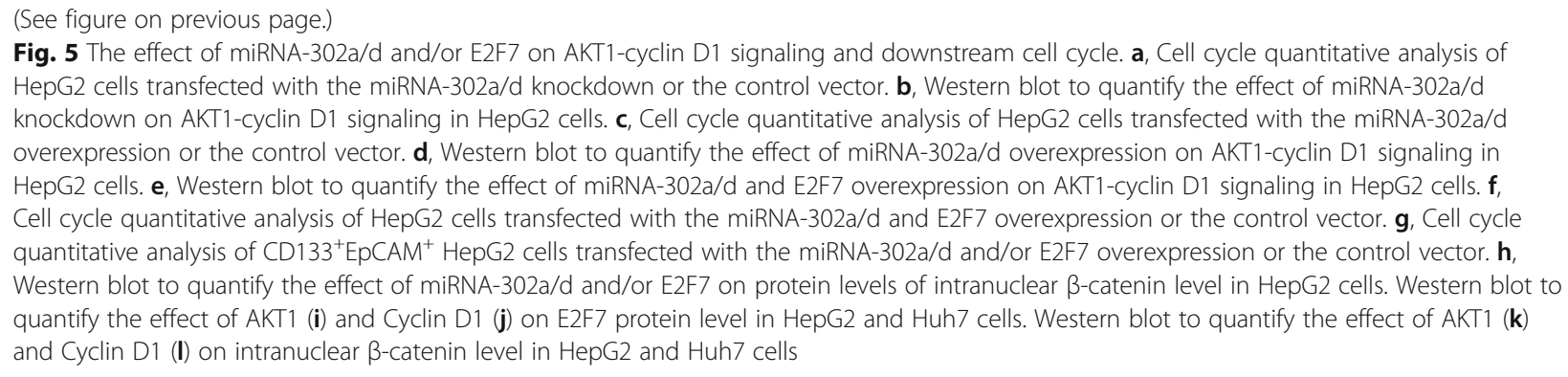

levels had significantly decreased OS $(P<0.001)$ and PFS $(P<0.001)$ (Fig. 6h), which suggested that E2F7 and miRNA-302a/d might have potential prognostic value and could be useful as tumor biomarkers for the diagnosis of HCC patients.

\section{Discussion}

Recent experimental evidence has shown that CSCs show higher tumorigenic potential and resistance to chemo/ radiotherapy compared to non-CSCs [32]. These features indicate that CSCs are involved in the development, progression, recurrence, and metastasis of tumors [33], suggesting that molecular and pathological characterization of CSCs is important to improve the prognoses of cancer patients. However, the precise roles and association between CSCs and the prognoses of patients are poorly understood, especially in HCC.

As regulators of diverse biological processes, different noncoding RNAs (ncRNAs) that negatively regulate gene expression, such as long ncRNAs (lncRNAs), are reported to be involved in the onset and development of HCC through LCSC regulation [34]. LncRNAs have the potential to serve as promising biomarkers for HCC progression and recurrence, as well as invasion and metastasis. Besides, lncRNAs are involved in HCC by affecting cell proliferation, apoptosis, and angiogenesis. Additionally, lncRNAs serve as a potential indicator of chemo-sensitivity and radio-resistance [35]. Meanwhile, lncRNAs exert their influence in interaction with proteins/miRNAs/mRNAs/ lncRNAs via epigenetic regulation/transcriptional regulation, as well as in regulation of autophagy, signaling pathways, and mRNA stabilization in HCC. Therefore, lncRNAs might be promising indicators for disease diagnosis, prognosis and recurrence prediction and potentially up-and-coming targets for therapeutic intervention of HCC [36].

In addition, miRNAs, a large number of small noncoding RNA genes found to be aberrantly expressed in various types of malignancies that function as either oncogenes or tumor suppressors, are a sophisticated tool in therapeutics and diagnostics, and remain a prime focus among cancer researchers [37]. Several miRNAs, which are involved in stemness maintenance and differentiation, have been identified to play a critical role in regulating $\mathrm{HCC}$ tumorigenesis and drug resistance signaling networks [38]. Therefore, targeting LCSCs and elucidating the underlying mechanisms of miRNA in LCSCs may improve diagnostic and therapeutic strategies for HCC [39].

$\mathrm{HCC}$ is a primary liver tumor that causes high mortality and remains a global challenge with the current limited treatments available. Recent studies indicate that HCC arises from LCSCs leading to tumor heterogeneity [40]. Expression of some liver CSC markers such as CD133 and EpCAM has been reported to be associated with tumor angiogenesis, low response rates to chemotherapy, and poor overall prognoses in patients with HCC [41]. Moreover, HCC patients with high levels of circulating LCSCs were found to have higher recurrence rates than those with lower levels of CSCs [42]. Therefore, the expression of liver CSCs markers and their extraordinary characteristics can serve as potential prognostic markers and therapeutic target in these patients.

The miRNA-302 family was previously identified to be epigenetically silenced in various types of cancer and to play important roles in tumor development and progression [43]. The miRNA-302 family is significantly downregulated in human colorectal cancer, osteosarcoma, and glioblastoma tissues [44-46]. MiRNA-302 inhibits the tumorigenicity of endometrial cancer cells by suppressing cyclin D1 and CDK1 [47]. MicroRNA-302a was reported to suppress prostate tumor cell proliferation by inhibiting $\mathrm{AKT}$, resulting in subsequent alterations of the AKT-GSK3 $\beta$-cyclin D1 and AKT-p27 pathways [48]. Besides, overexpression of miR-302b suppresses HCC growth via targeting the EGFR/AKT2/CCND1 pathway [49]. These studies suggested that the miRNA-302 family plays an important role in tumorigenesis and progression. However, the clinical significance of the miRNA-302 family in HCC, and the molecular mechanisms underlying the deactivation of its target genes in tumorigenesis and drug resistance derived by LCSCs still require elucidation.

In this study, we used tumor sphere formation to enrich LCSC cells and found that the miRNA-302 family was weakly expressed in LCSC cells as well as in HCC tumors. Moreover, patients with lower miRNA-302a/d expression 


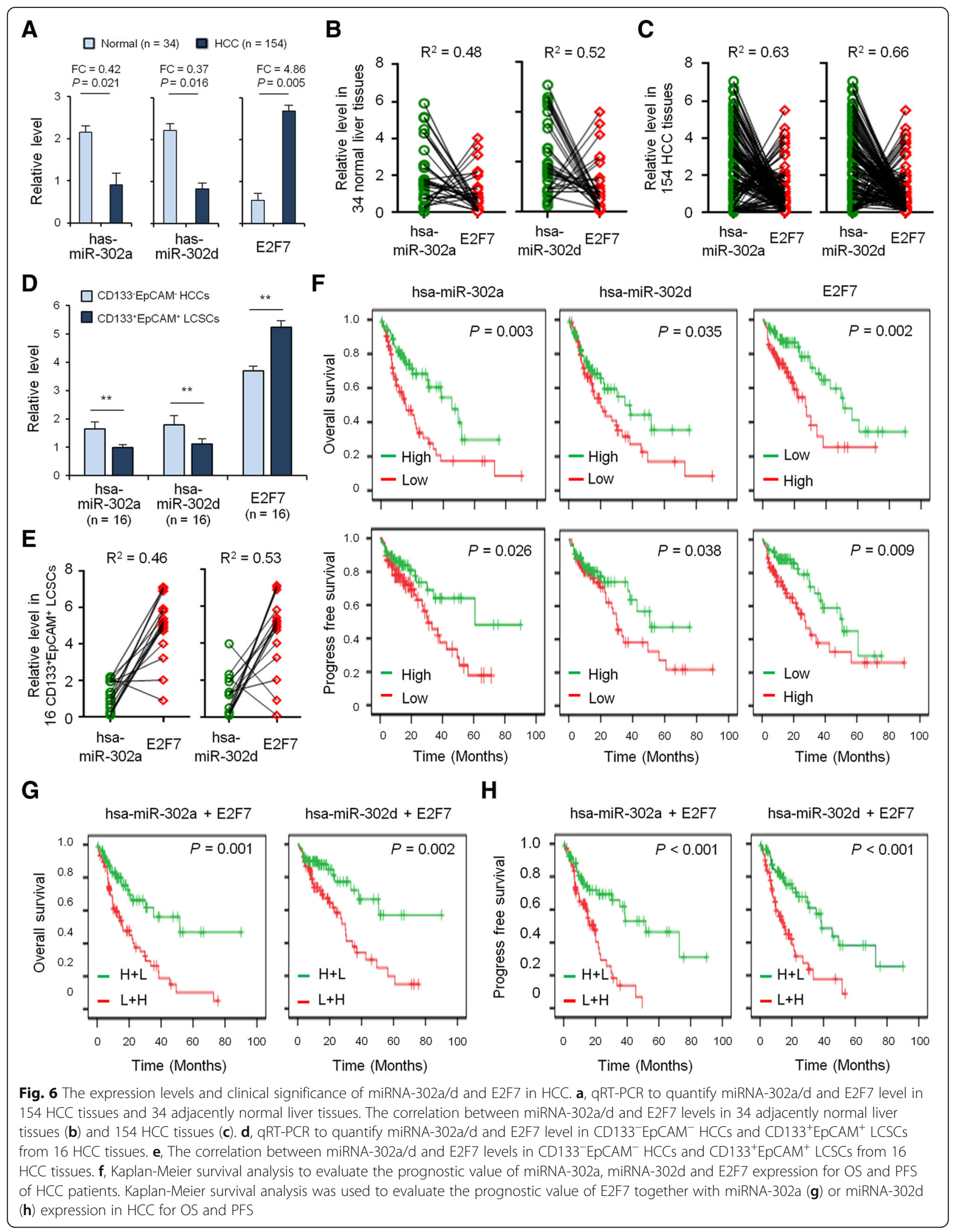


had shorter OS and PFS. We also identified that miRNA-302a/d inhibited HCC cell proliferation, tumor sphere formation in vitro and tumor growth in vivo. These results suggest that the miRNA-302 family is an important suppressor of LCSCs. Therefore, the potential anti-tumor mechanism of the miRNA-302 family in regulating LCSCs was further studied.

To uncover the underlying mechanism, four target gene prediction websites were used to forecast target genes of miRNA-302a/d and potential candidate and an atypical E2F family member E2F7, which limits the expression of E2F1 and prevents E2F1-dependent apoptosis [50-52], was selected and monitored in HepG2 and Huh7 cells with knocked down and overexpressed miRNA-302a/d. In this context, the expression of E2F7 was markedly inhibited by miRNA-302a/d. Owing to the typical seed sequence in the 3'-UTR of E2F7, a direct role of miRNA-302a/d was naturally surveyed next. As expected, E2F7 was a direct downstream target of miRNA-302a/d, as demonstrated by luciferase assays.

The members of the E2F family function as transcription factors and are widely expressed in a number of tissues and organs, they have been reported to control the expression of genes and possess many regulatory functions related to cellular proliferation, differentiation, DNA repair, the cell cycle, and cell apoptosis [53]. To date, eight members of this family, E2F1 to E2F8, have been recognized. In general, E2F1, E2F2, and E2F3 are considered to be transcriptional activators, whereas E2F4, E2F5, and E2F6 play inhibitory roles in transcriptional expression of downstream target genes [54]. The atypical E2F family member E2F8 and E2F7 perform complementary and overlapping functions in many cell metabolisms, and serve as a unique repressive arm to balance the E2F transcriptional network that is critical for embryonic development and control of the E2F1-p53 apoptotic axis [55]. E2F8 was found to be markedly overexpressed in HCC to facilitate tumor occurrence and development via activation of an E2F1/cyclin D1 signaling pathway to regulate the G1- to $\mathrm{S}$-phase transition of cell cycle progression or transcriptionally suppress CDK1 to induce hepatocyte polyploidization [56]. Moreover, the miR-302-367 cluster was reported to directly downregulate both AKT1 and cyclin D1, and indirectly upregulated $\mathrm{p} 27^{\mathrm{Kip} 1}$ and $\mathrm{p} 21^{\mathrm{Cip} 1}$, leading to the suppression of cancer cell proliferation [47], which is accordance with our data (Fig. 4).

In this study, E2F7 was found to be overexpressed in LCSCs and HCC tissue and had an inverse relationship with miRNA-302a/d. Our results further implied that E2F7 could be modulated by miRNA-302a/d during HCC cells proliferation and apoptosis driven by LCSCs. More interestingly, E2F7 overexpression could activate AKT1-cyclin D1 signaling and the downstream cell cycle, and the levels of intranuclear $\beta$-catenin were strikingly enhanced.
Moreover, the feedforward AKT/CCND1 axis regulates E2F7 signaling dependent on its effects on cellular proliferation and the cell cycle, which results in positive E2F7/AKT/ $\beta$-catenin/CCND1 feedback signaling to promote the self-renewal ability and cell cycle entry of LCSCs to act as enhancers for cell cycle progression and hepatocarcinogenesis.

To further evaluate their clinical signatures, miRNA302a/d and E2F7 were divided into high- and lowexpressing groups in HCC patients. In this context, E2F7 was highly expressed in HCC tissues when compared with normal liver tissues, and high levels of E2F7 in tumor tissues had poor prognostic values on the OS of HCC patients. Furthermore, concomitant low expression of miRNA-302a/d and high expression of E2F7 correlated with shorter median OS and PFS in HCC patients, suggesting miRNA-302a/d is a key regulator of HCC stemness via targeting the E2F7.

\section{Conclusions}

Taken together, our findings indicate that miRNA-302a/d can inhibit the stemness and proliferation of HCC cells through targeting E2F7 and downstream AKT/ $\beta$-catenin/ CCND1 signaling and may play an essential role in HCC progression suggesting that miRNA-302a/d and E2F7 may be promising therapeutic targets for $\mathrm{HCC}$ patients.

\section{Additional file}

Additional file 1: Table S1. miR-302a/d and E2F7 expression and clinicopathological characteristics of 154 HCC patients. Table S2. Realtime PCR primers used in this study. Figure S1. Expression of CSC Markers and miRNA-302 family in LCSCs. Figure S2. Expression of CSC Markers and miRNA-302 family during LCSCS differentiation. Figure S3. Validation of the correlation of miRNA-302a/d and E2F7 level. Figure S4. Biological role of miRNA-302a/d and E2F7 in HCC in vitro. (DOCX 1899 kb)

\section{Abbreviations}

AJCC: American Joint Commission on Cancer; DFS: Disease-free survival; E2F7: E2F transcription factor 7; HCC: hepatocellular carcinoma; KEGG: Kyoto Encyclopedia of Genes and Genomes; LCSCs: Liver cancer stem cells; miRNA: MicroRNA; OS: Overall survival; qPCR: Quantitative PCR; RIP: RNA immunoprecipitation; TNM: Tumor-node-metastasis

\section{Acknowledgments \\ We would like to thank Dr. Wei Zhang for data analysis and critical discussion of the manuscript.}

\section{Funding}

This study was supported partly by grants from the National Natural Science Foundation of China (81772932, 81472202, 81201535, 81302065, 81671716, 81301993,81372175 and 81472209), The Fundamental Research Funds For the Central Universities (22120170212 and 22120170117), Shanghai Natural Science Foundation (12ZR1436000), Shanghai Municipal Commission of Health and Family Planning (201540228).

\section{Availability of data and materials}

The datasets supporting the conclusions of this article are included within the article and Supplementary material. 


\section{Novelty \& Impact Statements}

MiR-302a/d inhibits stemness and proliferation of HCC cells by targeting E2F7 and its downstream AKT/ $\beta$-catenin/CCND1 signaling pathway. Concomitant low expression of miR-302a/d and high expression of E2F7 correlated with a shorter median OS and PFS in HCC patients. MiRNA-302a/d and E2F7 may be prognostic predictors of HCC.

\section{Authors' contributions}

YSM, ZWL, ZYC, YF, JZ and DF designed the study. YSM, GXL, FY and DF performed the cytological experiments. YSM, ZYC, JZ and DF performed the statistical analyses and interpreted the data. YSM, XLC, XMZ and DF are involved in patient recruitment. ZWL, YF, JZ and DF contributed to study materials and consumables. YSM, ZYC, JZ and DF wrote the manuscript. YSM, ZWL, FY and ZYC contributed equally to this work. All authors agreed with the results and conclusions.

\section{Ethics approval and consent to participate}

The study was approved by the Ethics Committee of Shanghai Tenth People's Hospital, Tongji University School of Medicine (SHSY-IEC-P-15-19). Each participant provided a written informed consent before participating in this study. All specimens were handled and made anonymous according to ethical and legal standards.

\section{Consent for publication}

Not applicable.

\section{Competing interests}

The author declare that they have no competing interests

\section{Publisher's Note}

Springer Nature remains neutral with regard to jurisdictional claims in published maps and institutional affiliations.

\section{Author details}

'Central Laboratory for Medical Research, Shanghai Tenth People's Hospital, Tongji University School of Medicine, Shanghai 200072, China. ²Department of Nuclear Medicine, Shanghai Tenth People's Hospital, Tongji University School of Medicine, Shanghai 200072, China. ${ }^{3}$ Shanghai Engineering Research Center of Molecular Therapeutics and New Drug Development, College of Chemistry and Molecular Engineering, East China Normal University, Shanghai 200062, China. ${ }^{4}$ Department of Pathology, Shanghai Tenth People's Hospital, Tongji University School of Medicine, Shanghai 200072, China. ${ }^{5}$ Department of Biobank, China-Japan Union Hospital, Jilin University, Changchun 130033, China. ${ }^{6}$ Department of Radiology, Jiangxi Provincial Tumor Hospital, Nanchang 330029, China. ${ }^{7}$ Department of Digestive Surgery, Rui Jin Hospital, Shanghai Jiao Tong University School of Medicine, Shanghai 200025, China.

Received: 17 July 2018 Accepted: 2 October 2018

Published online: 16 October 2018

\section{References}

1. Lee D, Xu IM, Chiu DK, Lai RK, Tse AP, Lan Li L, Law CT, Tsang FH, Wei LL, Chan CY, Wong CM, Ng IO, Wong CC. Folate cycle enzyme MTHFD1L confers metabolic advantages in hepatocellular carcinoma. J Clin Invest. 2017:127(5):1856-72

2. Ma Y, Zhang H, Xiong C, Liu Z, Xu Q, Feng J, Zhang J, Wang Z, Yan X. CD146 mediates an E-cadherin-to-N-cadherin switch during TGF- $\beta$ signaling-induced epithelial-mesenchymal transition. Cancer Lett. 2018;430:201-14

3. Wang Y, Ma YS, Fang Y, Wu SD, Liu LL, Fu D, Shen XZ. Regulatory T cell: a protection for tumor cells. J Cell Mol Med. 2012;16(3):425-36.

4. Wu SD, Ma YS, Fu D, Shen XZ. Role of the microenvironment in hepatocellular carcinoma development and progression. Cancer Treat Rev. 2012;38(3):218-25

5. Liu LL, Fu D, Ma YS, Shen X. The power and the promise of liver cancer stem cell markers. Stem Cells Dev. 2011;20(12):2023-30

6. Lv H, Lv G, Han Q, Yang W, Wang H. Noncoding RNAs in liver cancer stem cells: the big impact of little things. Cancer Lett. 2018;418:51-63.

7. Liang Z, Kong R, He Z, Lin LY, Qin SS, Chen CY, Xie ZQ, Yu F, Sun GQ, Li CG, Fu D, Jiang GX, Chen J, Ma YS. High expression of miR-493-5p positively correlates with clinical prognosis of non small cell lung cancer by targeting oncogene ITGB1. Oncotarget. 2017:8(29):47389-99.

8. Hou LK, Ma YS, Han Y, Lu GX, Luo P, Chang ZY, Xie RT, Yang HQ, Chai L, Cai MX, Wu TM, Yu F, Qin SS, Lv ZW, Wu CY, Fu D. Association of microRNA-33a molecular signature with non-small cell lung cancer diagnosis and prognosis after chemotherapy. PLoS One. 2017:12:e0170431.

9. Yang H, Li Y, Zhong X, Luo P, Luo P, Sun R, Xie R, Fu D, Ma Y, Cong X, Li W. Upregulation of microRNA-32 is associated with tumorigenesis and poor prognosis in patients with hepatocellular carcinoma. Oncol Lett. 2018;15(4): 4097-104.

10. Ma YS, Wu TM, Lv ZW, Lu GX, Cong XL, Xie RT, Yang HQ, Chang ZY, Sun R, Chai L, Cai MX, Zhong XJ, Zhu J, Fu D. High expression of miR-105-1 positively correlates with clinical prognosis of hepatocellular carcinoma by targeting oncogene NCOA1. Oncotarget. 2017;8(7):11896-905.

11. Wang XF, Zhu YZ, Ma YS, Wang J, Zhang F, Xia Q, Fu D. The role of cancer stem cells in cancer metastasis: new perspective and progress. Cancer Epidemiol. 2013:37(1):60-3.

12. Xie RT, Cong XL, Zhong XM, Luo P, Yang HQ, Lu GX, Luo P, Chang ZY, Sun $R$, Wu TM, Lv ZW, Fu D, Ma YS. MicroRNA-33a downregulation is associated with tumorigenesis and poor prognosis in patients with hepatocellular carcinoma. Oncol Lett. 2018;15(4):4571-7.

13. Nwosu ZC, Battello N, Rothley M, Piorońska W, Sitek B, Ebert MP, Hofmann U, Sleeman J, Wölfl S, Meyer C, Megger DA, Dooley S. Liver cancer cell lines distinctly mimic the metabolic gene expression pattern of the corresponding human tumours. J Exp Clin Cancer Res. 2018;37(1):211.

14. Huang Q, Zhang XW, Ma YS, Lu GX, Xie RT, Yang HQ, Lv ZW, Zhong XM, Liu T, Huang SX, Fu D, Xie C. Up-regulated microRNA-299 corrected with poor prognosis of glioblastoma multiforme patients by targeting ELL2. Jpn J Clin Oncol. 2017;47(7):590-6.

15. Shah R, Tanriverdi K, Levy D, Larson M, Gerstein M, Mick E, Rozowsky J, Kitchen R, Murthy V, Mikalev E, Freedman JE. Discordant expression of circulating microrna from cellular and extracellular sources. PLoS One. 2016; 11:e0153691.

16. Chen X, Zhang S, Wang Z, Wang F, Cao X, Wu Q, Zhao C, Ma H, Ye F, Wang $H$, Fang Z. Supervillin promotes epithelial-mesenchymal transition and metastasis of hepatocellular carcinoma in hypoxia via activation of the RhoA/ROCK-ERK/p38 pathway. J Exp Clin Cancer Res. 2018;37(1):128.

17. Yang Y, Zhu J, Zhang T, Liu J, Li Y, Zhu Y, Xu L, Wang R, Su F, Ou Y, Wu Q. PHD-finger domain protein 5A functions as a novel oncoprotein in lung adenocarcinoma. J Exp Clin Cancer Res. 2018;37(1):65.

18. Fu D, Ma YS, Wu W, Zhu XC, Jia CY, Zhao QL, Zhang CY, Wu XZ. Cell-cycledependent $P C-P L C$ regulation by $A P C / C^{C d c 20}$-mediated ubiquitinproteasome pathway. J Cell Biochem. 2009;107(4):686-96.

19. Lv D, Ma QH, Duan JJ, Wu HB, Zhao XL, Yu SC, Bian XW. Optimized dissociation protocol for isolating human glioma stem cells from tumorspheres via fluorescence-activated cell sorting. Cancer Lett. 2016; 377(1):105-15.

20. Yu J, Lei R, Zhuang X, Li X, Li G, Lev S, Segura MF, Zhang X, Hu G. MicroRNA182 targets SMAD7 to potentiate TGF $\beta$-induced epithelial-mesenchymal transition and metastasis of cancer cells. Nat Commun. 2016;7:13884.

21. Paladini L, Fabris L, Bottai G, Raschioni C, Calin GA, Santarpia L. Targeting microRNAs as key modulators of tumor immune response. J Exp Clin Cancer Res. 2016:35:103.

22. Ma YS, Huang T, Zhong XM, Zhang HW, Cong XL, Xu H, Lu GX, Yu F, Xue $\mathrm{SB}, \mathrm{LV}$ ZW, Fu D. Proteogenomic characterization and comprehensive integrative genomic analysis of human colorectal cancer liver metastasis. Mol Cancer. 2018;17(1):139.

23. Yuan H, Li N, Fu D, Ren J, Hui J, Peng J, Liu Y, Qiu T, Jiang M, Pan Q, Han Y, Wang X, Li Q, Qin J. Histone methyltransferase SETD2 modulates alternative splicing to inhibit intestinal tumorigenesis. J Clin Invest. 2017;127(9):3375-91.

24. Zhang B, Fu D, Xu Q, Cong X, Wu C, Zhong X, Ma Y, Lv Z, Chen F, Han L, Qian M, Chin YE, Lam EW, Chiao P, Sun Y. The senescence-associated secretory phenotype is potentiated by feedforward regulatory mechanisms involving Zscan4 and TAK1. Nat Commun. 2018;9(1):1723

25. Chi Y, Zhou D. MicroRNAs in colorectal carcinoma--from pathogenesis to therapy. J Exp Clin Cancer Res. 2016;35:43

26. Kim W, Khan SK, Gvozdenovic-Jeremic J, Kim Y, Dahlman J, Kim H, Park O, Ishitani T, Jho EH, Gao B, Yang Y. Hippo signaling interactions with Wnt/Bcatenin and notch signaling repress liver tumorigenesis. J Clin Invest. 2017 ; 127(1):137-52. 
27. Luo $P$, Yang $Q$, Cong LL, Wang XF, Li YS, Zhong XM, Xie RT, Jia CY, Yang HQ, Li WP, Cong XL, Xia Q, Fu D, Zeng QH, Ma YS. Identification of miR124a as a novel diagnostic and prognostic biomarker in non-small cell lung cancer for chemotherapy. Mol Med Rep. 2017;16(1):238-46.

28. Zhao L, Wang Y, Jiang L, He M, Bai X, Yu L, Wei M. MiR-302a/b/c/d cooperatively sensitizes breast cancer cells to adriamycin via suppressing Pglycoprotein(P-gp) by targeting MAP/ERK kinase kinase 1 (MEKK1). J Exp Clin Cancer Res. 2016:35:25.

29. Yan GJ, Yu F, Wang B, Zhou HJ, Ge QY, Su J, Hu YL, Sun HX, Ding LJ. MicroRNA miR-302 inhibits the tumorigenicity of endometrial cancer cells by suppression of cyclin D1 and CDK1. Cancer Lett. 2014;345:39-47.

30. Sun J, Shi R, Zhao S, Li X, Lu S, Bu H, Ma X, Su C. E2F8, a direct target of miR-144, promotes papillary thyroid cancer progression via regulating cell cycle. J Exp Clin Cancer Res. 2017;36(1):40.

31. Ozturk M, Arslan-Ergul A, Bagislar S, Senturk S, Yuzugullu H. Senescence and immortality in hepatocellular carcinoma. Cancer Lett. 2009;286(1): 103-13.

32. Chen B, Lee JB, Kang H, Minden MD, Zhang L. Targeting chemotherapyresistant leukemia by combining DNT cellular therapy with conventional chemotherapy. J Exp Clin Cancer Res. 2018;37:88.

33. Du L, Li YJ, Fakih M, Wiatrek RL, Duldulao M, Chen Z, Chu P, Garcia-Aguilar J, Chen Y. Role of SUMO activating enzyme in cancer stem cell maintenance and self-renewal. Nat Commun. 2016;7:12326.

34. DeWaal D, Nogueira V, Terry AR, Patra KC, Jeon SM, Guzman G, Au J, Long CP, Antoniewicz MR, Hay N. Hexokinase-2 depletion inhibits glycolysis and induces oxidative phosphorylation in hepatocellular carcinoma and sensitizes to metformin. Nat Commun. 2018:9(1):446.

35. Jing W, Gao S, Zhu M, Luo P, Jing X, Chai H, Tu J. Potential diagnostic value of IncRNA SPRY4-IT1 in hepatocellular carcinoma. Oncol Rep. 2016;36(2): 1085-92.

36. Zhu P, Wang Y, Wu J, Huang G, Liu B, Ye B, Du Y, Gao G, Tian Y, He L, Fan Z. LncBRM initiates YAP1 signalling activation to drive self-renewal of liver cancer stem cells. Nat Commun. 2016;7:13608.

37. Solé C, Larrea E, Di Pinto G, Tellaetxe M, Lawrie CH. miRNAs in B-cell lymphoma: molecular mechanisms and biomarker potential. Cancer Lett. 2017:405:79-89.

38. Wilson R, Espinosa-Diez C, Kanner N, Chatterjee N, Ruhl R, Hipfinger C, Advani SJ, Li J, Khan OF, Franovic A, Weis SM, Kumar S, Coussens LM, Anderson DG, Chen CC, Cheresh DA, Anand S. MicroRNA regulation of endothelial TREX1 reprograms the tumour microenvironment. Nat Commun. 2016:7:13597.

39. Fu XT, Shi YH, Zhou J, Peng YF, Liu WR, Shi GM, Gao Q, Wang XY, Song K, Fan J, Ding ZB. MicroRNA-30a suppresses autophagy-mediated anoikis resistance and metastasis in hepatocellular carcinoma. Cancer Lett. 2018; 412:108-17.

40. Chen J, Jin R, Zhao J, Liu J, Ying H, Yan H, Zhou S, Liang Y, Huang D, Liang $X$, Yu H, Lin H, Cai X. Potential molecular, cellular and microenvironmental mechanism of sorafenib resistance in hepatocellular carcinoma. Cancer Lett. 2015;367:1-11

41. Piao LS, Hur W, Kim TK, Hong SW, Kim SW, Choi JE, Sung PS, Song MJ, Lee BC, Hwang D, Yoon SK. CD133+ liver cancer stem cells modulate radioresistance in human hepatocellular carcinoma. Cancer Lett. 2012;315(2):129-37.

42. Shaw KL, Garabedian E, Mishra S, Barman P, Davila A, Carbonaro D, Shupien S, Silvin C, Geiger S, Nowicki B, Smogorzewska EM, Brown B, Wang X, de Oliveira S, Choi Y, Ikeda A, Terrazas D, Fu PY, Yu A, Fernandez BC, Cooper AR, Engel B, Podsakoff G, Balamurugan A, Anderson S, Muul L, Jagadeesh GJ, Kapoor N, Tse J, Moore TB, Purdy K, Rishi R, Mohan K, Skoda-Smith S, Buchbinder D, Abraham RS, Scharenberg A, Yang OO, Cornetta K, Gjertson D, Hershfield M, Sokolic R, Candotti F, Kohn DB. Clinical efficacy of genemodified stem cells in adenosine deaminase-deficient immunodeficiency. J Clin Invest. 2017;127(5):1689-899.

43. Liu N, Li J, Zhao Z, Han J, Jiang T, Chen Y, Hou N, Huang C. MicroRNA-302a enhances 5-fluorouracil-induced cell death in human colon cancer cells. Oncol Rep. 2017;37(1):631-9.

44. Yang X, Cui Y, Yang F, Sun C, Gao X. MicroRNA-302a suppresses cell proliferation, migration and invasion in osteosarcoma by targeting ADAM9. Mol Med Rep. 2017;16(3):3565-72

45. Ma J, Yu J, Liu J, Yang X, Lou M, Liu J, Feng F, Ji P, Wang L. MicroRNA-302a targets GAB2 to suppress cell proliferation, migration and invasion of glioma. Oncol Rep. 2017;37(2):1159-67.

46. Lee CC, Chen PH, Ho KH, Shih CM, Cheng CH, Lin CW, Cheng KT, Liu AJ, Chen KC. The microRNA-302b-inhibited insulin-like growth factor-binding protein 2 signaling pathway induces glioma cell apoptosis by targeting nuclear factor IA. PLoS One. 2017;12:e0173890.

47. Cai N, Wang YD, Zheng PS. The microRNA-302-367 cluster suppresses the proliferation of cervical carcinoma cells through the novel target AKT1. RNA. 2013;19(1):85-95.

48. Zhang GM, Bao CY, Wan FN, Cao DL, Qin XJ, Zhang HL, Zhu Y, Dai B, Shi GH, Ye DW. MicroRNA-302a suppresses tumor cell proliferation by inhibiting AKT in prostate Cancer. PLoS One. 2014;10:e0124410.

49. Mantel PY, Hjelmqvist D, Walch M, Kharoubi-Hess S, Nilsson S, Ravel D, Ribeiro M, Grüring C, Ma S, Padmanabhan P, Trachtenberg A, Ankarklev J, Brancucci NM, Huttenhower C, Duraisingh MT, Ghiran I, Kuo WP, Filgueira L, Martinelli R, Marti M. Infected erythrocyte-derived extracellular vesicles alter vascular function via regulatory Ago2-miRNA complexes in malaria. Nat Commun. 2016;7:12727.

50. Morgunova E, Yin Y, Jolma A, Dave K, Schmierer B, Popov A, Eremina N, Nilsson L, Taipale J. Structural insights into the DNA-binding specificity of E2F family transcription factors. Nat Commun. 2015;6:10050.

51. Kent LN, Rakijas JB, Pandit SK, Westendorp B, Chen HZ, Huntington JT, Tang X, Bae S, Srivastava A, Senapati S, Koivisto C, Martin CK, Cuitino MC, Perez M, Clouse JM, Chokshi V, Shinde N, Kladney R, Sun D, Perez-Castro A, Matondo RB, Nantasanti S, Mokry M, Huang K, Machiraju R, Fernandez S, Rosol TJ, Coppola V, Pohar KS, Pipas JM, Schmidt CR, de Bruin A, Leone G. E2f8 mediates tumor suppression in postnatal liver development. J Clin Invest. 2016;126(8):2955-69.

52. Aksoy O, Chicas A, Zeng T, Zhao Z, McCurrach M, Wang X, Lowe SW. The atypical E2F family member E2F7 couples the p53 and RB pathways during cellular senescence. Genes Dev. 2012;26(14):1546-57.

53. McNair C, Xu K, Mandigo AC, Benelli M, Leiby B, Rodrigues D, Lindberg J, Gronberg H, Crespo M, De Laere B, Dirix L, Visakorpi T, Li F, Feng FY, de Bono J, Demichelis F, Rubin MA, Brown M, Knudsen KE. Differential impact of RB status on E2F1 reprogramming in human cancer. J Clin Invest. 2018; 128(1):341-58.

54. Qin X, Livingston D, Kaelin WK Jr, Adams P. Deregulated transcription factor E2F-1 expression leads to S-phase entry and p53-mediated apoptosis. Proc Natl Acad Sci U S A. 1994;91(23):10918-22.

55. Wu X, Levine A. p53 and E2F-1 cooperate to mediate apoptosis. Proc Natl Acad Sci U S A. 1994:91(9):3602-6.

56. Yuzugullu H, Benhaj K, Ozturk N, Senturk S, Celik E, Toylu A, Tasdemir N, Yilmaz M, Erdal E, Akcali KC, Atabey N, Ozturk M. Canonical Wnt signaling is antagonized by noncanonical Wnt5a in hepatocellular carcinoma cells. Mol Cancer. 2009:8:90

Ready to submit your research? Choose BMC and benefit from

- fast, convenient online submission

- thorough peer review by experienced researchers in your field

- rapid publication on acceptance

- support for research data, including large and complex data types

- gold Open Access which fosters wider collaboration and increased citations

- maximum visibility for your research: over $100 \mathrm{M}$ website views per year

At $\mathrm{BMC}$, research is always in progress.

Learn more biomedcentral.com/submissions 